\title{
Investigation of Essential or Non-essential Character of Some Hardly Known Trace Elements for Plants
}

\author{
Andras S. Szabo \\ Faculty of Food Science, Food Physics Public Utility Foundation, Corvinus University of Budapest, Somloi str. 14-16, Budapest \\ 1118, HUNGARY
}

Received: February 10, 2015 / Accepted: February 21, 2015 / Published: February 28, 2015.

\begin{abstract}
The concentration distribution of essential and non-essential micro-elements of the tissues of healthy organisms shows significant difference. This fact can be used for clarification of the biological role of hardly known trace elements, as well, proving the essential or non-essential character. In case of essential elements the concentration range is rather narrow, the distribution is normal. In case of non-essential elements the interval is wide, the concentration-distribution is log-normal. Measurements and mathematical calculations were carried out for determination of the concentrations and concentration-distributions of some micro-elements, trying to clarify the essentiality or non-essential character of the investigated elements from point of view of plant physiology. Based on the measurements for radish $\mathrm{Li}$ and $\mathrm{Ni}$ seem to be non-essential trace elements, however in case of Sr the distribution curve suggests an essential character, because the concentration range is not wide.
\end{abstract}

Key words: Biological role, concentration-distribution, mathematical analysis, microelements, radish.

\section{Introduction}

It is well known that there are 92 different natural chemical elements in the periodical system-not including of course the man-made (artificial) transuranic elements - and from these 75 belong to the group of micro-elements. (There are 4 biogenic elements - C, H, O, N - 7 macroelements - K, Na, Ca, $\mathrm{Mg}, \mathrm{P}, \mathrm{S}, \mathrm{Cl}-6$ noble gases, which do not form chemical compounds.)

From biological point of view the microelements can be classified into the following groups:

- essential elements;

- probably essential elements, however the essentiality is not proven perfectly;

- stimulative (beneficial) elements;

- elements practically without biological effect (low level toxicity);

- toxic elements (high level toxicity).

Corresponding author: Andras S. Szabo, Ph.D., professor, research fields: food and sport science. E-mail: andras.szabo@uni-corvinus.hu.
Although the author does not want to go into details concerning this classification, however let the author mention the following things [1-10]:

(1) Today there are appr. 20 trace elements, which are definitely essential, however the number may be increased in future in consequence of the development of sensitive analytical techniques.

(2) Essential elements are constituents or activators of enzymes in the biological systems, so their presence is necessary to have normal speed of the biochemical processes.

(3) If the concentration (dose) is too high, all microelements are toxic, the real difference is the threshold-value.

(4) There are some differences between plants and animals (human beings) concerning the essentiality of the microelements, however the similarities are more typical than the differences, because similar enzymes act in the physiological processes.

Let the author mention that the experts of WHO, FAO and IAEA defined essentiality of a trace element 
as follows: "An element is considered essential to an organism when reduction of its exposure below a certain limit results consistently in a reduction in a physiologically important function, or when the element is an integral part of an organic structure performing a vital function in the organism".

In consequence of several regulatory mechanisms in case of an essential trace element (e.g. $\mathrm{Zn}, \mathrm{Cu}, \mathrm{Fe}$ ), its concentration from one organism (system, organ, tissue) to the next (belonging to the same species) is fairly constant. The variability among individuals is limited, and the concentration distribution is well approximated by a normal distribution [10, 12]. Essential elements were found to have normal concentration distribution (Gauss-distribution), whereas non-essential ones showed a log-normal distribution of the measured concentrations. Fig. 1 shows the connection between the physiological parameter (response) - in case of vegetables e.g. the yield and the concentration of the microelement in the soil (or nutrient solution) for essential elements. Fig. 2 is valid for non-essential elements.

Most essential elements (including of course the macro-elements, as well) have been found to have logarithmic standard deviations of 0.2 or less (factor 1.58), while non-essential elements usually exceeded
0.3 , corresponding to standard deviation factor greater than 2.00. Based on this fact, it is possible to determine the essential or non-essential character of many hardly known trace elements if the authors measure the concentration distribution of many biological samples of healthy organisms from different places [13-16]. In case of essential elements the difference between arithmetical and geometrical mean is small, but for non-essential elements the difference is significant.

\section{Materials and Methods}

Mathematical analysis of the measured concentration data was carried out to determine the essentiality or non-essential character for some hardly known trace elements, based on the concentration distribution. In this paper, the author will deal with questions only for plants, concerning the character of $\mathrm{Li}, \mathrm{Sr}$ and $\mathrm{Ni}$ as trace elements. For comparison the concentration distribution is given also for $\mathrm{Zn}$ (which is a well-known trace element). $\mathrm{Zn}$ is a typical essential element both for plants and animals.

As test plant radish (Raphanus sativus) was used, grown in Hungary, the investigated healthy edible radish samples originated from various cultivated places, representing various soil properties.

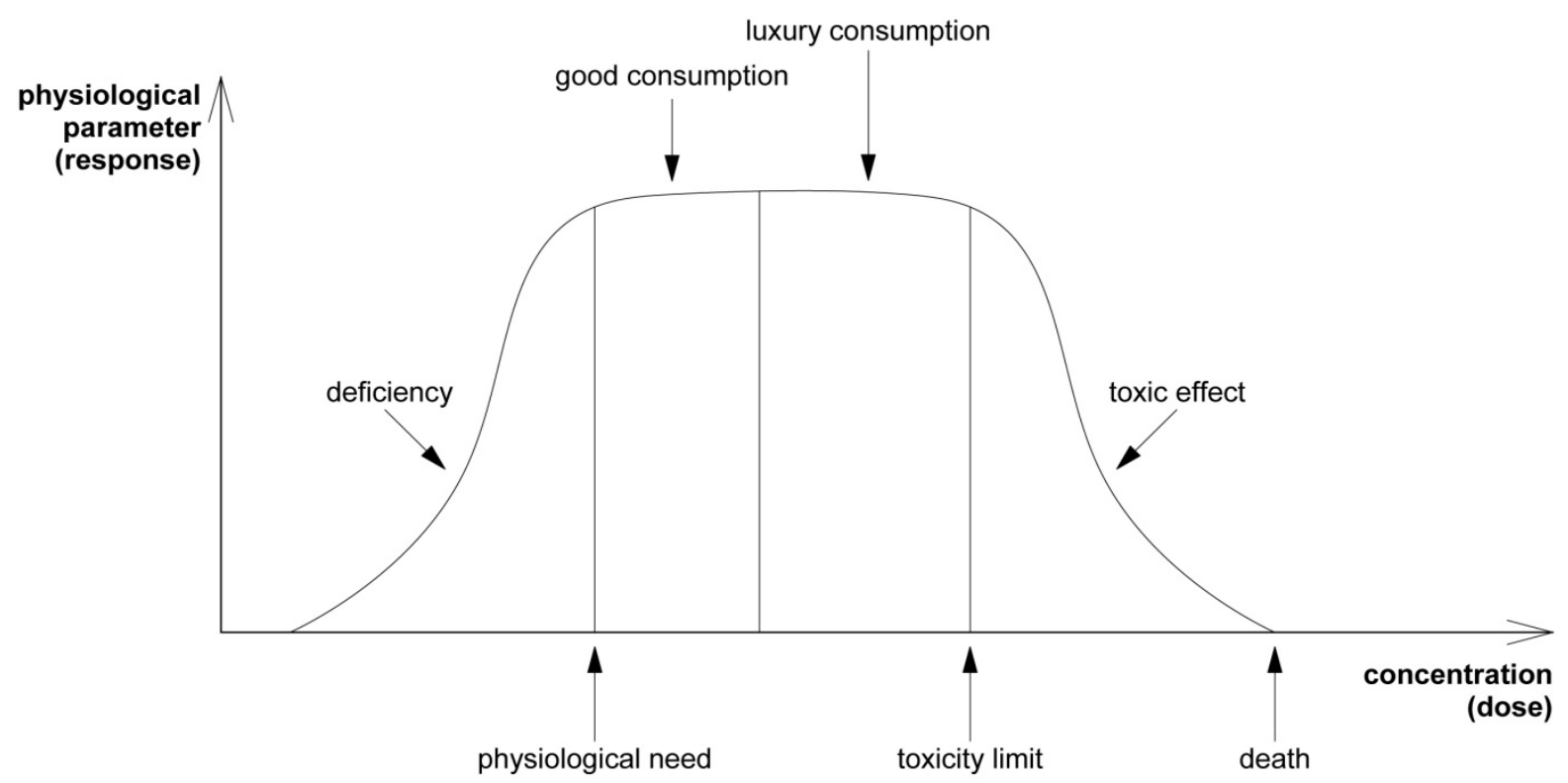

Fig. 1 Physiological parameter as a function of concentration for essential microelements. 


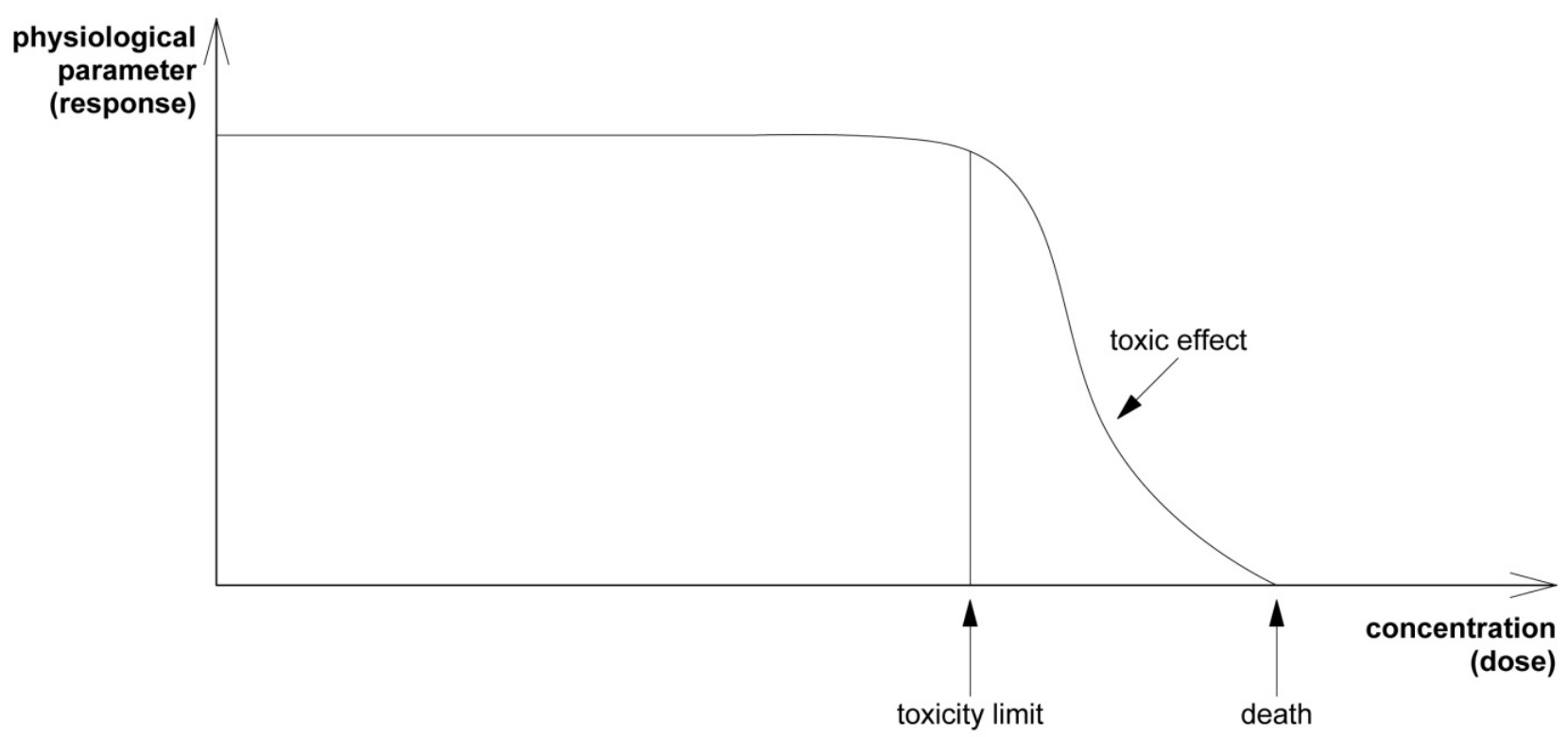

Fig. 2 Physiological parameter as a function of concentration for non-essential microelements.

Table 1 Li-content of radish $\left(10^{-6} \mathrm{~g} / \mathrm{g}\right.$ ash $)$.

\begin{tabular}{|l|l|}
\hline minimum & 20.04 \\
\hline maximum & 185.97 \\
\hline average & 104.20 \\
\hline standard deviation $(\mathrm{SD})$ & 64.52 \\
\hline arithmetical mean $\left(\mathrm{x}_{\mathrm{a}}\right)$ & 104.20 \\
\hline geometrical mean $\left(\mathrm{x}_{\mathrm{g}}\right)$ & 80.70 \\
\hline $\mathrm{x}_{\mathrm{g}} / \mathrm{x}_{\mathrm{a}}$ & 0.774 \\
\hline range for $\mathrm{f}=2.00(\operatorname{logf}=0.3)$ & $52.10-208.40$ \\
\hline range for $\mathrm{f}=1.58(\log \mathrm{f}=0.2)$ & $65.94-164.63$ \\
\hline percent of data out of range $\mathrm{f}=2.00$ & 20 \\
\hline percent of data out of range $\mathrm{f}=1.58$ & 40 \\
\hline
\end{tabular}

Table 2 Ni-content of radish (10-6 g/g ash).

\begin{tabular}{|l|l|}
\hline minimum & 8.77 \\
\hline maximum & 108.01 \\
\hline average & 58.72 \\
\hline standard deviation $(\mathrm{SD})$ & 42.61 \\
\hline arithmetical mean $\left(\mathrm{x}_{\mathrm{a}}\right)$ & 58.72 \\
\hline geometrical mean $\left(\mathrm{x}_{\mathrm{g}}\right)$ & 39.62 \\
\hline $\mathrm{x}_{\mathrm{g}} / \mathrm{x}_{\mathrm{a}}$ & 0.674 \\
\hline range for $\mathrm{f}=2.00 \quad(\log \mathrm{f}=0.3)$ & $29,35-117,42$ \\
\hline range for $\mathrm{f}=1.58(\operatorname{logf}=0.2)$ & $37,16-92,76$ \\
\hline$\%$ of data out of range $\mathrm{f}=2.00$ & 38 \\
\hline$\%$ of data out of range $\mathrm{f}=1.58$ & 75 \\
\hline
\end{tabular}

Table 3 Sr-content of radish (10-6 g/g ash).

\begin{tabular}{|l|l|}
\hline minimum & 212.01 \\
\hline maximum & 539.81 \\
\hline average & 337.07 \\
\hline standard deviation $(\mathrm{SD})$ & 101.89 \\
\hline arithmetical mean $\left(\mathrm{x}_{\mathrm{a}}\right)$ & 337.07 \\
\hline geometrical mean $\left(\mathrm{x}_{\mathrm{g}}\right)$ & 323.58 \\
\hline $\mathrm{x}_{\mathrm{g}} / \mathrm{x}_{\mathrm{a}}$ & 0.96 \\
\hline range for $\mathrm{f}=2.00 \quad(\log \mathrm{f}=0.3)$ & $168,54-674,14$ \\
\hline range for $\mathrm{f}=1.58(\operatorname{logf}=0.2)$ & $213,34-532,57$ \\
\hline$\%$ of data out of range $\mathrm{f}=2.00$ & 0 \\
\hline$\%$ of data out of range $\mathrm{f}=1.58$ & 7 \\
\hline
\end{tabular}

Table 4 Zn-content of radish (10-6 g/g ash).

\begin{tabular}{|l|l|}
\hline minimum & 119.96 \\
\hline maximum & 393.61 \\
\hline average & 224.19 \\
\hline standard deviation $(\mathrm{SD})$ & 82.07 \\
\hline arithmetical mean $\left(\mathrm{x}_{\mathrm{a}}\right)$ & 224.19 \\
\hline geometrical mean $\left(\mathrm{x}_{\mathrm{g}}\right)$ & 211.15 \\
\hline $\mathrm{x}_{\mathrm{g}} / \mathrm{x}_{\mathrm{a}} \quad 0.941$ \\
\hline range for $\mathrm{f}=2.00 \quad(\log \mathrm{f}=0.3)$ & $112,00-448,38$ \\
\hline range for $\mathrm{f}=1.58(\operatorname{logf}=0.2)$ & $141,89-354,22$ \\
\hline$\%$ of data out of range $\mathrm{f}=2.00$ & 0 \\
\hline$\%$ of data out of range $\mathrm{f}=1.58$ & 27 \\
\hline
\end{tabular}


For the chemical analysis of the samples different techniques (flame photometry, X-ray fluorescence, neutron activation analysis and ICP-AES method) were used.

\section{Results and Discussion}

Table 1 to 4 show the results of measurements and statistical analysis for $\mathrm{Li}, \mathrm{Sr}, \mathrm{Ni}$ and $\mathrm{Zn}$ content. The author can easily establish, that the range for $\mathrm{Li}$ and $\mathrm{Ni}$ is quite wide, and there are significant differences between the arithmetical $\left(\mathrm{X}_{\mathrm{a}}\right)$ and geometrical $\left(\mathrm{X}_{\mathrm{g}}\right)$ mean data. Considerable amount of measured data are out of the interval, characterized by factor 1.58 , or even 2.00. The ratio between the maximum and minimum data is 9.3 for $\mathrm{Li}$ and 12.3 for $\mathrm{Ni}$, so the difference is one order of magnitude. In case of $\mathrm{Sr}$ this ratio is 2.5 and for $\mathrm{Zn}$ (which is undoubtedly essential microelemnt) is 3.2 .

In the case of $\mathrm{Sr}$ the $\mathrm{X}_{\mathrm{a}}$ and $\mathrm{X}_{\mathrm{g}}$ values are near, the concentration range is rather narrow, the maximum and minimum concentration data practically show a coincidence with the values, determined by factor 1.58 . The results are rather similar for $\mathrm{Zn}$, having also a relatively narrow interval of concentration data.

The conclusion - based on the concentration distribution investigations - is the following: For plants $\mathrm{Li}$ and $\mathrm{Ni}$ are with high probability non-essential trace elements, however $\mathrm{Sr}$ seems to be essential.

\section{References}

[1] Bowen, H. J. M. 1972. The Biochemistry of the Elements. Nuclear Activation Techniques in the Life Sciences. Vienna: IAEA.
[2] Bowen, H. J. M. 1982. "Royal Society of Chemistry." Environmental Chemistry. London: Burlington House.

[3] Szabó, A. S., Kiss, B., and Liszonyi-Gacsályi, M. 1984. "New Results in the Research of Hardly Known Trace Elements." Budapest, 1984, ed.: I. Pais, p. 194-6.

[4] www.kau.edu.sa/trace elements vital for human body.

[5] www.colloidal-minerals-plus.com/NutritionalList.html (list of nutritional functions and deficiency symptoms)

[6] www.speclab.com/elements/strontium.htm

[7] Pais, I. 2003. "New Results in the Trace Element Research." In Proceedings of 10th Int. Trace Element Symp, 1-361.

[8] Goldhaber, S. B. 2003. "Trace Element Risk Assessment: Essentiality vs Toxicity." Regulatory Toxicology and Pharmacology 38 (2): 232-42.

[9] Fraga, C. G. 2005. "Relevance, Essentiality and Toxicity of Trace Elements in Human Health." Mol Aspects Med. 26: $235-44$.

[10] Capelli, R., Das, K., Pellegrini, R. D., Drava, G., Lepoint, G., and Miglio, C. et al. 2008. "Distribution of Trace Elements in Organs of Six Species of Cetaceans from the Ligurian Sea." Science of the Total Environment 390: 569-78.

[11] Heydorn, K. 1984. Neutron Activation Analysis for Clinical Trace Element Research. Florida: CRC Press.

[12] Mertz, W. 1998. "Review of the Scientific Basis for Establishing the Essentiality of Trace Elements." Biol Trace Elem Res. 66: 185-91.

[13] Szabo, A. S. 1996. "Determination of Essential or Non-essential Character of Some Hardly Known Trace Elements." In Proceedings of 7. Int. Symp. New Perspectives in the Research of Hardly Known Trace Elements, 39-46.

[14] Szabo, A. S. 2003. "Is Nickel an Essential Trace Element?" In Proceedings of 10th Int. Trace Element Symp. New Results in the Trace Element Research, 356-61.

[15] Szabo, A. S. 2013. "Essentiality of Trace Elements and Food Investigations." J. Food Investigations 59 (3): 95-105.

[16] Szabo, A. S., and Tolnay, P. 2014. "Investigation of Essentiality of Some Trace Elements." Metabolism 12 (5): 385-9. 